EETP Vol. 14, 2019, №. 1(51)

ISSN 1896-2327 / e-ISSN 2353-7787

DOI: $10.35765 /$ eetp.2019.1451.02

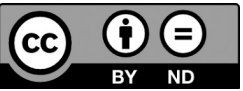

Submitted: 6.03 .2019

Accepted: 23.04 .2019

Suggested citation: Zdybel D. (2019). Rodzina jako przestrzeń socjalizacji poznawczej dziecka - o procesie przyswajania kulturowych narzędzi myślenia, „Edukacja Elementarna w Teorii i Praktyce", vol. 14, no. 1(51), pp. 21-39. DOl: 10.35765/eetp.2019.1451.02

\title{
Dorota Zdybel
}

ORCID: 0000-0003-3322-7570

The Faculty of Education

Jesuit University Ignatianum in Krakow

\section{Family as the Space of the Child's Cognitive Socialisation - on the Process of Acquiring Cultural Tools of Thinking}

$\begin{aligned} & \text { KEYWORDS } \text { ABSTRACT } \\ & \begin{array}{r}\text { cognitive } \\ \text { socialisation, tools of } \\ \text { thinking, cognitive } \\ \text { scaffolding, guided } \\ \text { participation, } \\ \text { apprenticeship } \\ \text { in thinking }\end{array} \quad \begin{array}{l}\text { action with the products of culture of a particular society in which } \\ \text { resources of knowledge and skills, and acquiring language symbols } \\ \text { with their ways of valuing and interpreting the world, but it also in- } \\ \text { clude the internalization of particular types of discursive formations } \\ \text { through which typically human abilities to metacognition, re-descrip- } \\ \text { tion of cognitive operations, and dialogic thinking, are developed. In } \\ \text { this sense, we may speak of the child's "cognitive socialisation" as the } \\ \text { process of growing into the culture of thinking of a given community. } \\ \text { The main objective of the article is to show the way such socialisation } \\ \text { functions in the family environment: from the broadest - polyadic } \\ \text { aspect (understood as "apprenticeship in culture"), to the most pro- } \\ \text { found, personal aspect understood as the "internalization" of cultural } \\ \text { procedures and tools of thinking. Based on the systematic analysis } \\ \text { of the available literature and examples of children's utterances, the }\end{array}\end{aligned}$


author presents typical features of family interactions facilitating building the cognitive scaffolding, as well as the signs of the process of familiarizing thinking tools in play that make it possible for the parents to consciously watch and stimulate little child's cognitive development in the situations that are natural for the family.

\section{Introduction}

The rapid development of modern civilisation forces changes from the structure and functioning of modern families. However, there are such areas and spaces of the family functioning which have always played their role, creating the network of everyday interactions responsible for the process of the child's cognitive socialisation understood as growing into the culture of thinking of a particular community and gradual acquisition of values, symbols, linguistic and thinking tools applied in this culture on the regular basis.

This article is to present the role of a family as the original environment of the child's cognitive socialisation, and to make the readers familiar with selected mechanisms of such socialisation, hidden in everyday situations, events and activities offered to the child by his or her closest environment. In a natural manner, the network of family relations activates the processes of shaping the mind's cognitive structures which occur "by the way", during everyday activities, making it possible for the child to watch and imitate adults who are cognitively more competent partners for them. Three levels of functioning of the mechanisms of cognitive socialisation shall be discussed in the article, according to Barbara Rogoff (1993): from the broadest one - the cultural (polyadic) level, understood as immersion in the "culture of thinking"; to the most profound - personal one, understood as the "acquisition" of cultural tools and procedures of thinking. On the basis of one of such tools, the author shall present the process of "familiarizing" cultural knowledge, giving it one's own meanings and transforming it into the personal, handy knowledge activated in an intuitive and automatic manner.

\section{The notion of cognitive socialisation}

Socialisation is traditionally associated with the process of the "acquisition of knowledge, communication competences, psycho-social skills, as well as the system of values and norms, resulting from the influence of the social and cultural environment" (Oleś 2018). However, contemporary science emphasizes the fact that the 
mechanisms of socialisation have a much more profound influence on the way an individual functions - an important part of the process is shaping (in a literal, neurobiological sense) the person's cognitive structures in a way that gives human cognition a unique nature. The child who functions and grows up in a particular culture interacts with its resources, both in the form of knowledge, values, symbols and traditions gathered by the previous generations, and in the form of patterns of thinking and communicating coded in those symbols. In this sense, interacting with a particular culture activates the processes of learning "relatively constant and ordered systems of cognitive behaviours due to which an individual obtains or modifies his or her knowledge in different situations" (Męczkowska-Christiansen 2015: 23). Such acquisition of cognitive competences is specified by Ziółkowski as "cognitive socialisation" (ibid), and J. Bruner says that human "intelligence, to a large extent, is the internalisation of tools given by culture" (Bruner 1978: 611). According to the intention of L.S. Wygotski, the term: "cultural tools" means "tools of the intellectual adaptation to the requirements of a given culture", i. e. specific means, things and symbolic systems used in a given society to communicate and analyse the reality, techniques of thinking, ways of solving problems, strategies of argumentation, etc. (quoted by: Filipiak 2012: 35). They may be:

physical or technical, e. g. a hammer, scissors, a computer, a touchscreen, a robot, etc.;

psychological: a language, ways of studying or memorizing (mnemotechniques), ways of justifying one's opinion, negotiating, etc.;

or symbolic, e. g. letters, mathematical symbols, programming languages, road signs, architectural schemes, maps, etc.

According to the contemporary research results, the process of acquiring and systematic using of such cultural tools has a profound, shaping influence not only on the person's noticeable behaviour or their way of thinking and valuing the world, but also on the neuroanatomic structure of human brain. Regular repetition of particular activities/operations of the mind stimulates and modifies the creation of synaptic connections in human brain, "formatting" it like a hard drive in a computer, i. e. preparing it for receiving and processing a particular type of data. The brain's synaptic plasticity is the basis for learning, and neuroanatomic research provides numerous proofs of the importance of such plasticity. The most popular example is the analysis of the hippocampus of London taxi drivers (more: Spitzer 2012: 153). It turned out that the regular activation of their hippocampus, forced by the regulations of the corporation which forbade them to use the GPS, resulted in a clear increase and specialisation of that area of the brain structures responsible for spatial orientation. In this sense we may assume that culture does not "equip" the man with meanings and symbols, providing the material which the mind later uses, but it "co-controls the 
human mind" (Męczkowska-Christiansen 2015: 22), giving its activity a uniquely human nature that makes us different from animals. According to many scientists, the key to such uniqueness is the network of social relations in which the man functions and due to which he learns how to share intentionality and attention (i. e. the ability to adopt the perspective of another person, understand their feelings, intentions and needs, to interpret the motifs of other people's acts and predict their reactions), formulate and fulfil common plans, cooperate with others and share responsibility with them (Tomasello 2002). Thus, the essence of cognitive socialisation is learning culturally shaped cognitive patterns understood as the ways of processing information obtained from the world, the ways of cooperating with others, planning and fulfilling common goals, as well as understanding what knowledge, learning and critical thinking is.

It is worth mentioning that, although the very term "cognitive socialisation" hardly ever occurs in pedagogical literature, the cultural context of the development of the man's cognitive skills and structures has been analysed by pedagogues and psychologists for a long time. The child's development and education has been considered from such a perspective by L.S. Wygotski, J. Bruner, Bronfenbrenner, S. Szuman, M. Przetacznik-Gierowska, M. Tomasello, and - at the moment - i. a. A. Brzezińska, E. Filipiak or D. Klus-Stańska. All those authors emphasize that culture defines the context of human development, i. e.:

on the one hand, it provides stimulation - it offers repeatable types of situations/ activities considered, in a given community, to be valuable and important for the child, and it blocks other situations that are perceived as improper or unnecessary. As a result of participating in such situations, the child experiences something that is preserved as a memory trace in the mind which constitutes the material for developmental changes - a building material of cognitive schemes coded in neural structures;

on the other hand, culture "provides symbolic tools necessary for processing and structuring (restructuring) the individual experience" (Przetacznik-Gierowska, Tyszkowa 1996: 120). In the course of socialisation, children "acquire symbolic systems including the conventions regulating the principles of coding (decoding) related meanings and senses, as well as hierarchies of values typical of a given culture, and, partially, the values themselves" (ibid: 106). As M. Tyszkowa emphasizes, the crucial condition for development is not only going through a particular set of experiences (experiencing and practising certain types of interactions and cognitive activities), but - first of all - acquiring the cultural tools of elaborating them and adopting as symbols. In future, those tools, including the underlying system of valuing and emotional interpretation/evaluation, shall become the regulator of 
further, independent actions of an individual, as well as the key factor of building the man's identity as a learning person (ibid: 106-107).

It is worth looking at the mechanisms of the so-called cognitive socialisation.

\section{Mechanisms of cognitive socialisation}

According to Barbara Rogoff (1993), the process of occurrence of developmental changes taking place during cognitive socialisation may be analysed in three different, but mutually conditioning and related levels of organisation: a cultural, interpersonal and personal (individual) level.

The cultural level may be compared to the apprenticeship while preparing for a particular profession (Rogoff 1993: 132-133). It is because its essence is "immersing" the child in the sociocultural environment which provides the patterns of socially organised activities, based on the traditions and norms of a given culture. On this level, an individual is an active watcher rather than an independent originator of actions. A social group (a community or institution) performs a dominant function, i. e. it determines the individual's objectives and organizes their actions, and, at the same time, it provides social support in the fulfilment of particular tasks, specifying the desired strategies of acting, cultural tools and systems of values. This way, the individual is gradually familiarised with the traditions and included into the community's action.

Nowadays, this area of socialisation is mainly fulfilled by educational institutions (preschool, school, Church, scouting, etc.) the description of which is outside the topic of this article. Nevertheless, it is worth mentioning that the very idea of "apprenticeship" has been known since ancient times, and it is still used as the educational model in artistic and scientific professions. Such model is highly effective, because it fills the gap that cannot be filled by any institution - what is missing in the official system of education is a close relationship with the "master" and the opportunity to accompany his/her everyday work in natural conditions. Lisa Hammond (2018), on the basis of her own experience of being an apprentice, and then the master of ceramics for others, believes that one of the greatest advantages of being an apprentice is the possibility to watch the whole creative process: from the emergence of the idea, through processing it and searching for new solutions, experimenting with materials and tools, until the final reception of the completed work by the recipient. The apprentice has a unique opportunity to see the ups and downs of the creative process, not only in the technological aspect - the use of specific materials, tools and techniques, but also in the emotional dimension - co-experiencing the master's emotions, watching how he/she deals with creative blockades, their sources of inspiration, their way of looking 
for new ideas, etc. Apprenticeship also has a social dimension - it makes it possible to meet people involved in the process of exposing the work, publishing it, preparing exhibitions, and getting materials and sources of financing the artistic work, which after completing the period of apprenticeship - makes it easier to start the professional career. What is interesting is the fact that the relation between the master and the student makes the educational process mutual - both sides of the process are changing $^{1}$. The apprentice is not the only one who profits from the relation (although his/ her profits are more obvious); also the master undergoes changes, though the presence of the apprentice influences him/her in a more indirect, subtle and emotional manner. An apprentice may become the source of inspiration or disappointment, a challenge for interpreting the world, a partner or an opponent in a dispute. He or she leaves a trace in the master's life and consciousness, becoming a catalyst of new reflections, creating contexts for overcoming one's own habits and going beyond one's schemes of actions, he/she provides surprises, and opens new fields of experience or exploration.

Naturally, a little child is not much different than an adult apprentice. The differences that occur are mainly those that result from a different level of cognitive abilities, such as the ability to focus attention, manage one's own memory or control one's emotions, the awareness of one's own needs and possibilities, etc. Nevertheless, there are profound similarities between the child and the adult apprentice which make it possible to use the metaphor of the "apprenticeship in thinking" as a valuable model explaining the development of children's cognitive structures. Two elements seem to be of key importance here:

active nature of the learning process - a child is not a passive recipient of the cultural message. He/she actively searches for new knowledge and experience, he/ she often initiates educational situations, he/she does not learn through receiving knowledge in a ready-made form, but interprets information from the environment, gives meanings to watched situations and experiences, constructs his/her knowledge on their own. The child is a "builder and architect of their own mind" (Dylak 2013: 170);

- culturally structured nature of educational situations - such situations not only have a natural structure embedded in the course of the social life, but they also offer a direct, practical usefulness - real meaningfulness (contrary to school situations, which are designed for teaching purposes and often unrelated to real life).

\footnotetext{
What is interesting, B. Rogoff claims that mutual education of both sides involved in the model of apprenticeship in culture is noticeable even in educational institutions which are gradually changing, adjusting their structures and ways of acting to the needs and possibilities of the new generations of participants. For example, a kindergarten learns to maintain a website and communicate with parents through the electronic media not because it wants or needs new means of action, but because of the expectations of the new generations of parents.
} 
Another, interpersonal level of cognitive socialisation is determined by the system of interpersonal relations of dyadic nature available in a given environment (Rogoff 1993: 134). B. Rogoff describes it as "guided participation" (1990: 18), emphasizing that also on this level the child participates in a culturally significant activity, but their role is much more active - from the watcher, he/she becomes a partner in the process of cooperation, and he/she is co-responsible for the course and effects of such partnership. This level is mainly activated in the family community, creating the natural frame of everyday interactions. Guided participation involves the children into the process of noticing, verbalising and solving everyday problems, giving a structure to their activity and modulating the scope of responsibility in such a way that the situation is comfortable for the child but - at the same time - it requires certain effort and constitutes a challenge, extending the child's understanding of the context, developing their skills and thus leading to general development. As we can see, the idea of guided participation uses the notion of the "zone of proximal development" by Wygotski, understood as the "dynamic area of susceptibility to learning cultural skills" (1978: 86).

The presence of an adult, more culturally competent guardian, who knows the child and their current skills very well, makes it possible to slightly raise the level of difficulty in a given situation, constructing a "cognitive scaffolding" adjusted to the child's ability to learn. This unique combination of comfort and requirements, the sense of security in a known environment and intellectual stimulation, makes it possible for the child to make a step towards development - to notice a more mature perspective of perceiving a problem and practice thinking tools necessary for dealing with the problem. B. Rogoff emphasizes three crucial features of such interaction which give it developmental value: a/ linking new knowledge and skills with those the child already has; $\mathrm{b} /$ obtaining an intersubjective level of understanding meanings; and c/gradual transfer of responsibility for a task from the adult partner to the child (1990). A brief description of the above mentioned aspects is as follows:

Ad a. The first important aspect of guided participation is building the bridge between what is known and what is new, i. e. between the child's personal knowledge and the adult's cultural knowledge. While explaining a task to the child, the adult clearly points to the internal connections, similarities between what the child already knows or can do on their own, and what the new task requires - the adult explains the way in which the new task is similar to what has already been done. The adult models the child's behaviour by showing the first step and supports the child in making further steps - he structures the situation, dividing the problem into smaller and easier stages of development and, at the same time, showing both its internal logic and the strategy of solving it. This way, the adult provides an instruction in a verbal form and emotional support, i. e. through everything she/he does - verbally 
and non-verbally - the adult makes the child think they shall manage to deal with the problem, strengthen their motivation, and builds the child's sense of competence. Cooperating in this manner, the adult and the child remain in the zone of shared attention and involvement, which makes it possible to reduce fear and focus on the task. D. Klus-Stańska describes this type of interaction as "cognitive partnership" (2002: 117-118), indicating that its developmental value is related to the adult's constant concern for the child's cognitive autonomy, respect for the child's strategies of reasoning, giving the child the right to make mistakes and correct them on their own. This way, the child can experience cognitive control over the situation; he/she may freely express their doubts, ask questions, and actively manage the process of building their own knowledge. Dialogic nature of the relation enables "flexible confrontation of the child with personal experience or public knowledge" of the adult partner, which makes it possible for the child to "become mentally familiar" with the public/cultural knowledge and to include it into the personal system of meanings (Klus-Stańska 2002: 118). Klus-Stańska shows that developmental advantages of such a relation are revealed on two interconnected levels:

on the personal level, cognitive partnership leads to shaping the sense of responsibility for one's own learning, which makes it possible for the child to experience the right to resistance, having their own opinion, expressing doubts, asking questions, etc. This way, an active attitude towards learning and the awareness of one's role in this process is gradually being shaped;

on the cognitive level, it makes it possible to experience cognitive control over one's knowledge, which leads to the awareness of its scope and level of certainty: What do I know, and what I don't know? What do I know for sure? How do I know that? What do I fail to understand or what am I not sure of? The very act of asking such questions activates the adult's epistemological reflection and makes the child believe that knowledge is not always sure, indisputable or objective.

A clash with the perspective of understanding the world which is different than ours is a necessary condition for the development of the child's theories of mind, i. e. it makes it possible for the child to become aware of the subjective, interpretative nature of knowledge (Carpendale, Chandler 1996: 1704). In other words, it helps the child discover that people may attach different meanings to the same facts or events. The ability to explain each of those meanings and predict the influence of a specific interpretation on further behaviour of a given person becomes the beginning of the awareness of the fact that knowledge is not objective - that it is not a passive reflection of the external world, but a construction, a subjective interpretation carried out by the mind of a specific person.

A little later, the child discovers that there are such areas of knowledge in which the epistemological status is unclear, unexplained, unknown even to the specialists, or 
interpreted in different manners, depending on the social and cultural context - that there is so-called interpretative knowledge (Klus-Stańska 2002: 120). The research proves that the child's early contact with such kind of knowledge is particularly important for the development of critical thinking, the ability to evaluate the accuracy of arguments, understanding the difference between a proof and justification / opinion (cf. Kuhn 2000: 178-181). As D. Klus-Stańska indicates, interpretative knowledge:

\begin{abstract}
(...) is developed in the course of deliberations, critical reflection, i. e. considerations focused on the complexity of the world and the phenomena occurring in the world, its ambiguity, complexity of many judgements and decisions, the fact that many convictions are hypothetical, placing interpretations in various kinds of contexts (...); it does not involve criticising in a literal sense (although it accepts such criticising), but it includes the ability to discuss opinions, notice numerous implications of different situations, understanding contradictory interests of people involved in those situations, anticipating broad consequences of our decisions, indicating the differences between the intentions and results of actions, etc. (2002: 120).
\end{abstract}

In other words, it is knowledge that cannot be transferred in a ready-made form, as it requires an active thinking effort, independence and critical judgement of the arguments the person notices. However, it is a very important order of thinking in the modern world, "a way of cognitive taming of the reality" (2002: 122) and dealing with its ambiguity. The lack of such experience results in the rigidness of thinking, susceptibility to false interpretations offered by pseudo-authorities, and the inability to think independently and solve cognitive problems.

Ad b. Another very important aspect of guided participation is experiencing "intersubjectivity of meanings". C. Trevarthen defines intersubjectivity as "simultaneous recognition and control of cooperative intentions and common patterns of awareness" (in: Rogoff 1990: 71). The basis of intersubjectivity understood in such a manner is the joint focus of attention determined by the interlocutors' shared "coordinates" - common points of reference around which the talk strategy is constructed. It is not clear whether the ability to create common meanings is inborn, or whether children learn it through imitating adults' behaviour. Nevertheless, the research shows that such ability appears quite early in the child's development, taking the form of exchanging behaviours, i. e. playing the role of a sender, and then the role of a recipient in the process of exchanging verbal or non-verbal messages. In this sense, C. Trevarthen proves that "the primary intersubjectivity appears between the $2^{\text {nd }}$ and $3^{\text {rd }}$ month of life, when the baby and his/her guardian - in a face-to-face relation - vocalise to each other alternately (...), i. e. become involved in an exchange that may be called protoconversation" (in: Białecka-Pikul et al. 2014: 52). Secondary intersubjectivity appears about the $9^{\text {th }}$ month of life, when the child becomes able to participate in the 
game "give and throw", where the alternate roles of the sender and the recipient are integrated around the common point of reference (a toy).

As we can see, early forms of intersubjectivity are possible to achieve through nonverbal means of expression (such as: eye contact, facial expression, touch, etc.), but only after learning the language communication goes up to a higher level. It is because language offers not only more precise tools of expressing and communicating meanings, but it also exerts a profoundly modifying influence on the child's cognition, giving it uniquely human nature (Tomasello 2002: 282): it provides tools of categorisation and symbolisation of experience, it makes it possible to detach cognitive processes from the direct, sensual context (from what is "here and now"), it offers tools of description and interpretation of those areas of reality which are not available to sensual cognition (moods, emotions, mental processes, etc.). As M. Tomasello proves, "it is true that language does not create new cognitive processes out of nothing, but when children participate in interactions with others, adopting their point of view and communication conventions, new forms of cognitive representations are created which have no counterparts among other animal species. It is possible because of the fact that linguistic symbols are both intersubjective and include a perspective" (2002: 282-283):

intersubjectivity of linguistic symbols means that they are shared by a certain community of people, creating a network of common meanings due to which it is possible to form conclusions related to other people's communication intentions, to predict others' reactions to our behaviour and utterances, and to specify and negotiate the common understanding of the situation;

- "perspectivity" of language means that through language the same phenomenon may be constructed (presented and interpreted) in many different ways - depending on the person and their communication intentions. Through the participation in the dialogue, the child discovers that someone's perspective of seeing and interpreting the experienced phenomena may be different than his/her own, and the child gradually learns to reconcile different perspectives - he/she becomes sensitive to other interpretations of the reality, understands their role as the motifs of someone else's actions. In this sense, language is the basis for intersubjectivity of meanings constructed in the course of a dialogue.

Ad c. The most characteristic feature of guided participation is the internal structure of interaction, specified as "cognitive scaffolding" (a scaffolding for thinking and learning). It is a sequence of steps/stages of common action through which the adult directs the process of problem-solving, adjusting subsequent phases to the child's changing (increasing) sense of competence, enabling a gradual transfer of responsibility for the actions and results from the adult to the child (Rogoff 1990: 93-94). It is very difficult to describe the structure of such an interaction - contrary to what 
the name "scaffolding" suggests, it is not a rigid, repeatable scheme. On the contrary it is a flexible, "child-following" strategy of acting which E. Filipiak calls "proactive intervention" or "sensitive control of teaching" (2015: 22), emphasizing that it is not only about dividing the task into parts adequate to the child's perceptive and cognitive abilities, but, first of all, it includes the recognition of the zone of proximal development of skills involved in the task and flexible adjustment of further stages of the work to such a zone, as well as forms of support which is provided. J. Bruner describes six functions of the adult tutor in shaping the cognitive scaffolding (in: Rogoff 1990: 94) ${ }^{2}$ :

Recruiting the child's interest in the task - building the space for common action and directing the child's attention to important elements: "See what I have prepared...";

simplifying the task, i. e. reducing the number of steps necessary for solving it and indicating further stages: "First we shall..., and then...";

demonstrating an idealized version of necessary actions: "I will show you how to do this. Look! I'll start and you shall continue... Try doing the same we did before";

maintaining motivation and interest, building emotional support: "That's very nice! Think what you should do now. I wonder what we shall get in the end?";

- indicating the differences between the perfect and the obtained result: "See what else can we improve... We have a little mistake here, let's try to fix it... Maybe we can try doing it in a different way?";

- helping in controlling frustrations and stress-management: "You can do it! You have almost finished... You did great, working all by yourself!".

Thus, the main objective of the scaffolding is helping the child with making another step in the development of thinking, leading the child from the phase of observing, through the cooperation with the adult, to self-regulation and the ability to work on their own. A key role in this process is played by language. On the one hand, its role is of a formative nature: through language the adult builds a scaffolding for the child's thinking, provides explanations and instructions, and regulates behaviour. As the research of $\mathrm{M}$. Tomasello shows, this regulating speech of adults is subject to internalization, becoming the origins of the development of self-regulation - the child "is trying to understand what the adult means, adopting the adult's point of view (i. e. simulating the adult's perspective)" (2002: 256), and then the child transfers those rules onto another situation which is similar in structure but solved on his/ her own, repeating the adult's utterances and instructions in the form of a so-called self-regulating speech (as if the child was an instructor for him/herself). "This process

2 A clear description of the tutor's tasks (different strategies of helping) in school conditions is presented by Filipiak (2012: 57-59). 
makes it possible for the child to analyse their own thoughts and convictions in a way similar to that of the adult who did it previously during the discourse. As a result, mechanisms of self-regulation and metacognition are created, and we can notice them already at the end of early childhood" (Tomasello 2002: 254). Such a process is confirmed by the fact that more or less at the same time children try to teach or regulate learning of other children, also through the repetition of utterances heard from adults.

On the other hand, according to the research by L. S. Wygotski, the key to selfregulation is transferring activities from the external (interpsychological) level to the internal (intrapsychological) level - the speech that used to be external, directed towards others, gradually becomes internal speech, directed towards oneself, constituting a kind of a "draft / rough copy of thoughts" (in: Filipiak 2015: 27). The child's verbal reasoning takes the form of an "inner dialogue", due to which it is possible not only to consciously direct one's thinking, but reflect on the course and result of thinking. This way, language starts to perform a planning and controlling function for thinking.

\section{The internalization of cultural tools of thinking - from imitation to possession}

The deepest, personal level of experiencing developmental changes is related to how an individual modifies his/her skills and way of understanding the situation under the influence of participating in cultural and interpersonal activities. Its essence is the obtainment of fluency in performing specific cognitive actions, and the transfer of the proficiency onto other communication situations. B. Rogoff calls this process "the internalization" (1993: 141), emphasizing that it is different than interiorization understood according to the definition by L.S. Wygotski. In the concept of L.S. Wygotski, interiorization means making something interior, i. e. transferring the activities into the internal, psychological sphere. The internalization means "taking something over for one's own use", making something a part of one's own psychological structure (in: Wertsch 1998: 53). Its essence includes the personal processes of transformation, i. e. integrating and transforming previous experiences, as a result of which the individual's functioning is brought to a new, higher level of development.

Here is an example of the process of internalization of one of the cultural thinking tools - a "list" as a planning tool. 


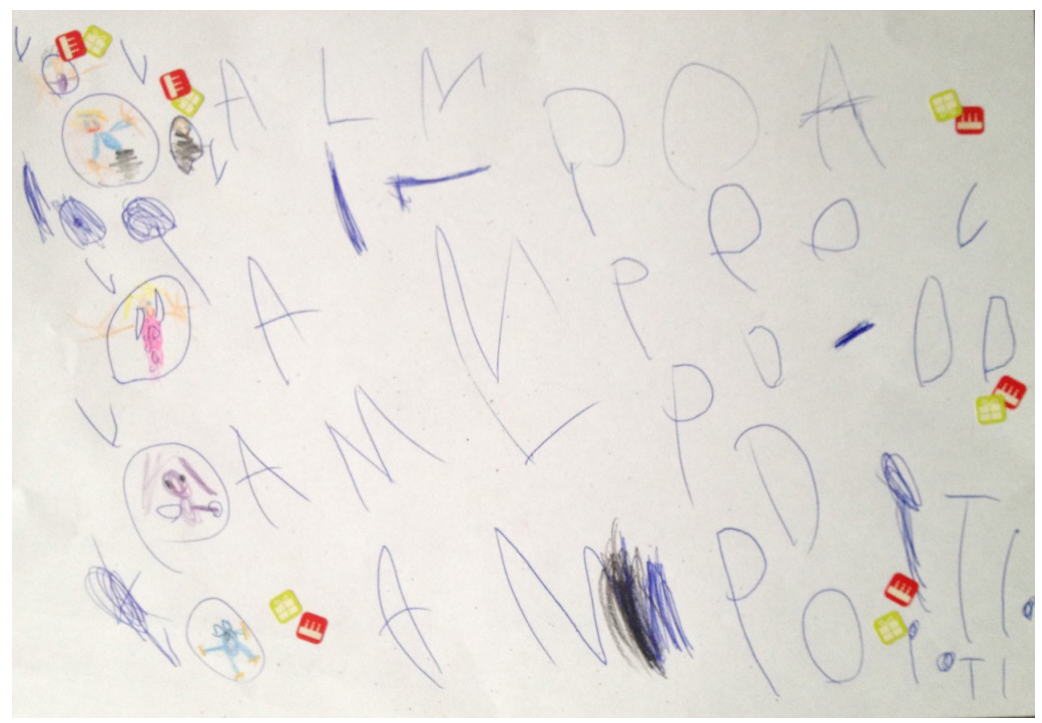

Fig. 1. A list of guests invited for a doll's birthday party (the stage of imitation of a cognitive activity in a thematic play) - author's own archive

The above figure presents a list of guests invited for a doll's birthday party - the guests were presented in the form of pictures accompanied by the notes on the guest's behaviour and the present he/she brought. On the left side of the paper we can read that the guests who participated in the party were: Ken (who brought 3 presents marked with stickers), Barbie in a pink dress, "Violet" (a purple, plush rabbit) and "Berry" - a plush blueberry. The picture was made by a 5-year-old girl a few days after her birthday party in the organisation of which she actively participated (taken by the hand by her parents, she chose the room, the menu, decorations - usually according to the pattern: "What do you prefer: $\mathrm{x}$ or $\mathrm{y}$ ?"). Although the picture seems unimportant and unintelligible for a person who does not know what it shows, it played a very important role in a thematic play as a tool of planning. From that moment on, planning became an inseparable element of many other plays. It appeared, e. g. as a list of patients waiting for a visit at the vet, a list of things to be packed before going on holiday, a shopping list, etc. A "list" as a part of the planning procedure and an important thinking tool was not only transformed in the play and enriched with the girl's own meanings, but it was also transferred to other, non-birthday contexts of action. Figure 2 presents the example of such a transfer. This time, the girl asked her babysitter for help with writing the title (the girl coloured the letters herself) and writing 
"real" names of people who were invited (first, she drew their portraits herself). On top of the list there is a portrait of the author and the signature she made on her own. It is easy to notice that, although figure no 1 is the effect of imitation - a reflection of what the parents prepared with the child while planning the birthday party, figure 2 illustrates the process of internalising a thinking tool, reflecting full understanding of its essence, as well as extending its role and usefulness in the process of thinking and a transfer into a completely new context of action. The internalization of a tool is also reflected in figure 3 , and this time it takes a symbolic form of a note hanged on the door of the child's room. The writing says: "You mustn't! You mustn't come in without knocking. You mustn't overhear. You mustn't disturb”. 


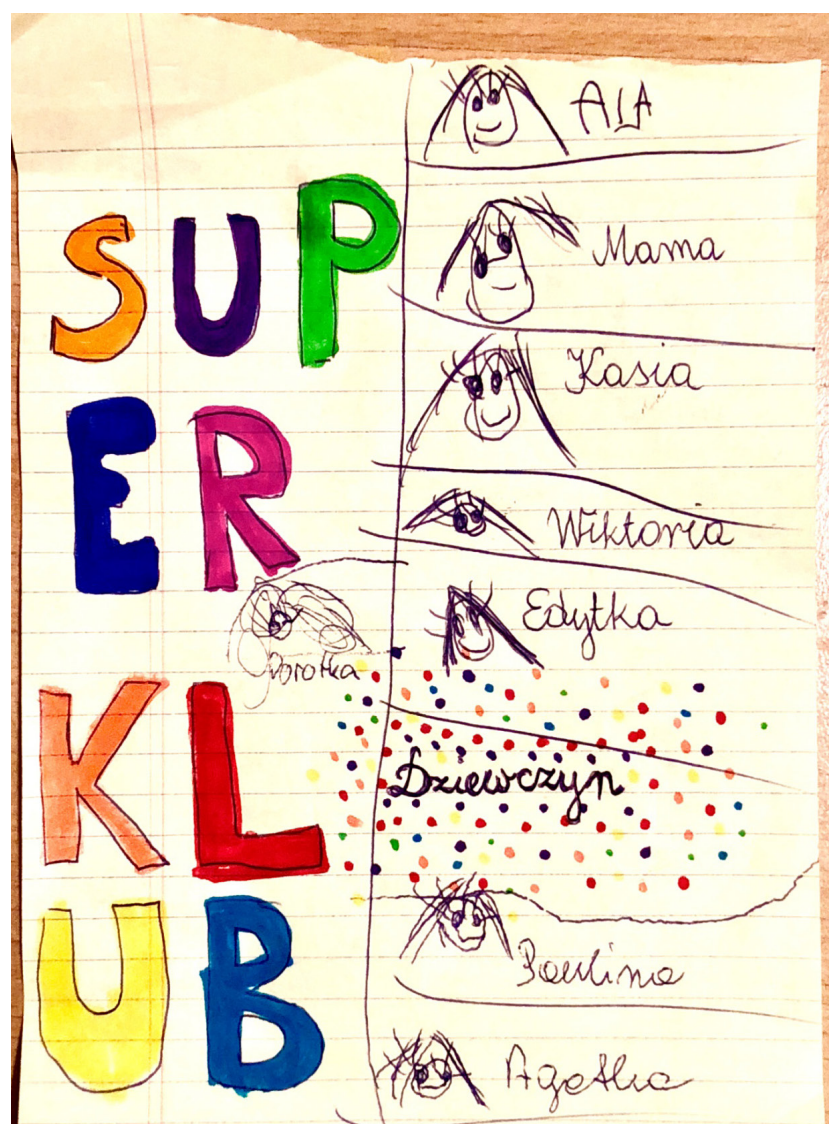

Fig. 2. The process of transferring the "list" as a thinking tool - extending the role and usefulness, transferring to another context of action (author's own archive) 


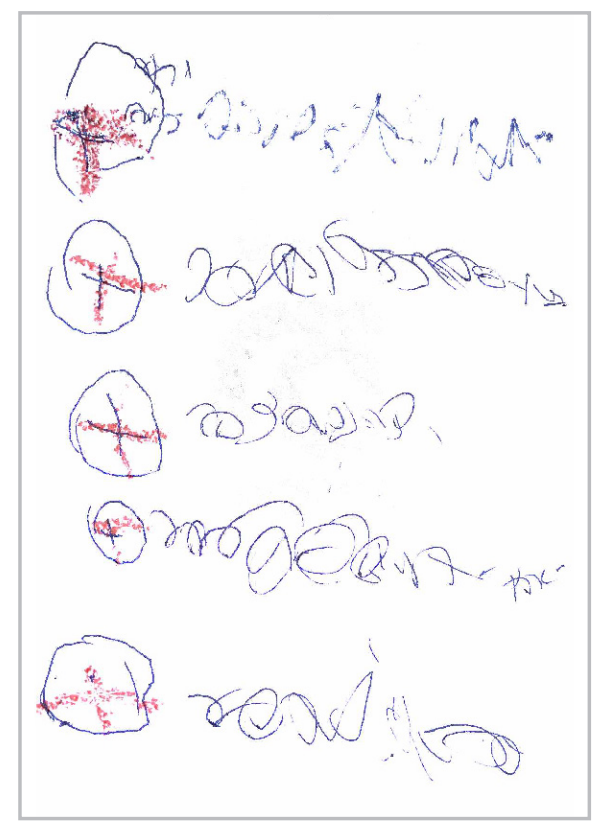

Fig. 3. The stage of the acquisition of a thinking tool - giving it one's own meanings, taking as one's own (author's own archive)

Therefore, the acquisition of a cultural tool does not only mean proper understanding of its meaning, objective and scope of usage, but it also means making it a part of the individual style of action, giving it personal content, a personal form, adjusting it to the context of action so that it can effectively match the adopted objectives. Only such usage of the tool makes it an important element of our experience, and, at the same time, a tool for collecting and organizing further experiences.

\section{Conclusion}

It is worth to emphasize that, although the patterns of interactions described in the article may refer to the parent, the adult guardian/teacher, elder siblings or peers in the kindergarten, the key role in the child's early socialisation is played by the family. Not only is it the first community of communicating minds with which the child meets, but it also influences the child in the most sensitive period for learning - when neurobiological structures of the child's brain are being shaped. 
According to M. Białecka-Pikul, the bond between the parent and the child, as well as the quality of talks carried out in the family, is responsible for the quality of family support in the process of shaping the child's cognitive abilities (2012: 131-137). A very important aspect is the so-called "attentiveness towards the child's mind", i. e. the tendency to treat the child as a separate person enjoying full rights - a person who has their needs, emotions, desires and convictions, even if they cannot fully control them yet (ibid: 132). Such perception of the child makes the parent pay attention to the child's states of mind, as well as explain and describe the child's behaviour referring to mental rather than behavioural characteristics: Are you sad or tired? Don't you like this game? Why are you angry? The parent directly names the feelings, desires or needs of the child, giving them vocabulary necessary for describing mental states and processes. As a result, the child learns to see "the difference between what is external, visible and material in human behaviour, and what constitutes an internal, mental, and symbolic being" (Wellman 1985: 169). Such differentiation is the beginning of the development of early, naïve theories of the mind - the first turning point in the series of "breakthroughs in the epistemological development" of the child described in the books (Hofer 2004: 45).

The attentiveness towards the child's mind results in the stabilisation of a certain style of upbringing which is characterised by a gentle balance between the level of emotional warmth and actions aimed at discipline. As M. Białecka-Pikul justly notices, "keeping balance between giving the child freedom and simultaneous control over his/ her behaviour from the perspective of the expected upbringing results, especially the system of values, requires from the parent a reflection on both the current behaviour of the child and the parent's own expectations" (2012: 133). Thus, such balance requires attentiveness towards one's own mind, understood as the ability to focus on the present moment and to reflect on one's desires and feelings: what am I directed by? Why am I angry and why do I shout? What do I want to achieve? What traits do I want to shape in my child? It requires reflection on one's own cultural potential, on the tools and values used by the parent in the process of raising the child. This way, socialisation processes takes the form of mutual shaping - the child changes the parents' mind as strongly as the parents who change and socialise the child's mind.

To sum it up, the mechanisms of early cognitive socialisation have a powerful formative strength, as - in quite a short time - they transform a little child from a helpless being to a thinking person who is aware of his/her process of thinking. Culture and its social conventions, symbols and cognitive tools, discursive situations and language structures exert a great modifying influence on the child's cognition, giving it nature characteristic of a human being. As M. Tomasello rightly notices, learning the language of symbols and related ways and forms of thinking is only possible due to a long, constant interaction with adult guardians. "The child growing 
up on a desert island, lacking the contact with other people, would not become - as Rousseau predicted - a «natural» man, a man free from limitations, but - according to Geertz - he or she would become a kind of a degenerate, a being not fully human, who would be void of intentionality and morality" (Tomasello 2002: 285-286).

\section{Bibliography}

Białecka-Pikul M. (2012). Narodziny i rozwój refleksji nad myśleniem, Kraków: UJ.

Białecka-Pikul M., Białek A., Stępień-Nycz M., Karwala M. (2014). Odkrywanie kompetencji komunikacyjnych niemowląt. Skala Wczesnej Komunikacji Spotecznej jako przyktad narzędzia pomiarowego, „Psychologia Rozwojowa”, Tom 19, nr 3.

Carpendale J.I., Chandler M.J. (1996). On the Distinction between False Belief Understanding and Subscribing to an Interpretive Theory of Mind. "Child Development" vol. 67, p. 1686-1706.

Dylak S. (2013). Architektura wiedzy w szkole, Warszawa: Difin SA.

Filipiak E. (2012). Rozwijanie zdolności uczenia się. Z Wygotskim i Brunerem w tle, Gdańsk: GWP.

Filipiak E. (2015). Budowanie rusztowania dla myślenia i uczenia się dzieci w perspektywie spoteczno-kulturowej teorii Lwa S. Wygotskiego, [w:] E. Filipiak (red.), Nauczanie rozwijające we wczesnej edukacji wedtug Lwa S. Wygotskiego. Od teorii do zmiany w praktyce, Bydgoszcz: Projekt Akademickie Centrum Kreatywności. Agencja Reklamowo-Wydawnicza ArtStudio.

Hofer B., Epistemological Understanding as a Metacognitive Process: Thinking Aloud During Online Searching, "Educational Psychologist" 2004, 39 (1), p. 43-55.

Klus-Stańska D. (2002). Konstruowanie wiedzy w szkole, Olsztyn: Wydawnictwo UWM.

Kuhn D. (2000, October). Metacognitive Development, "Current Directions in Psychological Science", vol. 9, nr 5, p. 178-181.

Męczkowska-Christiansen A. (2015). Socjalizacja poznawcza jako (d)efekt ksztatcenia szkolnego (na tle rozważań nad kulturowym kontekstem konstruowania struktur poznawczych człowieka, „Problemy Wczesnej Edukacji”, nr 1 (28).

Oleś M., Socjalizacja, Stownik PWN https://encyklopedia.pwn.pl/haslo/socjalizacja;3977112.html [dostęp dnia: 20.08.2018].

Przetacznik-Gierowska M., Tyszkowa M. (1996). Psychologia rozwoju człowieka, T. 1. Zagadnienia ogólne, Warszawa: PWN.

Rogoff B. (1993). Children's Guided Participation and Participatory Appropriation in Sociocultural Activity, [w:] R.H. Wozniak, K.W. Fisher (red.), Development in Context. Acting and Thinking in Specific Environments, Hillsdale: Lawrence Erlbaum Associates Publishers.

Rogoff B. (1990). Apprenticeship in Thinking. Cognitive Development in Social Context, New York: Oxford University Press.

Tomasello M. (2002). Kulturowe źródta ludzkiego poznawania, Warszawa: PIW. 
Vygotsky L.S. (1978). Mind in Society. The Development of Higher Psychological Processes, Cambridge: Harvard University Press.

Wellman H.M. (1985). The Child's Theory of Mind: The Development of Conceptions of Cognition, [w:] S.R. Yussen (red.), The Growth of Reflection in Children, Orlando: Academic Press.

Wertsch J.V. (1998). Mind as Action, Oxford University Press, Oxford: New York.

\section{ADDRESS FOR CORRESPONDENCE}

Dr Dorota Zdybel

The Faculty of Education

Jesuit University Ignatianum in Krakow e-mail: dorota.zdybel@ignatianum.edu.pl 